\title{
IMPLEMENTATION OF LICENCE AUTOMATION SYSTEM
}

\author{
Mrs.Ramya.D ${ }^{1}$,Mrs.A.Santhi MaryAntony ${ }^{2}$ Dr.D.Godwin Immanuel ${ }^{3}$, and Mr.Nirmal Raj ${ }^{4}$ \\ (ramya.devasahayam@gmail.com ${ }^{1}$,msanthimary@gmail.com ${ }^{2}$,dgodwinimmanuel@gmail.com, ${ }^{3}$ nirmalraj \\ .eee@sathyabama.ac.in $\left.{ }^{4}\right)$ \\ Department of Electrical and Electronics Engineering, \\ Sathyabama Institute of Science and technology,chennai,India
}

\begin{abstract}
This work deals with the automatic process of license for driving system. Normally, during test a candidate has to drive with specific rules or else he will be disqualified .So manual monitoring is required. To overcome this ,an Arduino system with sensors has been developed to have an eye on the candidate, then it was processed by connecting to laptop or PC. Once the registered canditate undergone for license screening the persons identity can be be verified by finger print sensing. The candidates performance will be recoganised spontaneously and the results will be generated either selected or rejected.
\end{abstract}

Keywords: sensor, license, test track, Arduino

\section{Introduction}

The technology has reached heights in day to day life and everything is automated .Here in this work InfraRed sensors are used on track to monitor the vehicle movement and tests driving skills of the candidate. And also the authority person needs not to monitor the candidate who enters for the license test. Before entering for the driving license test candidate has to be registered and authenticated using fingerprint sensor. During driving the person is monitored by the sensors[1]. The Arduino monitors various sensors and verifies sensor readings with preset criteria and generates the results, which will be displayed on the computer. The license is able to be provided for the qualified candidates.Un expectedly the candidate unable to clear all the test the candidate should reappear again on the nextcycle[2].

\section{Existing work}

A survey on license holders shows that $54 \%$ of the peoples are not having proper knowledge about driving[3]. In present scenario, there is a possibility of human error like improper observation, corruptions and favoritism by the examiners [4]. More over manyskilled driving inspectorsare needed to monitor the entire process in the field.Hence the available procedure is not efficient and it takes more time to complete the entire process.

This system is not reliable.It takes more time to generate the license and the person who monitors the performance needs to stand for long time. 


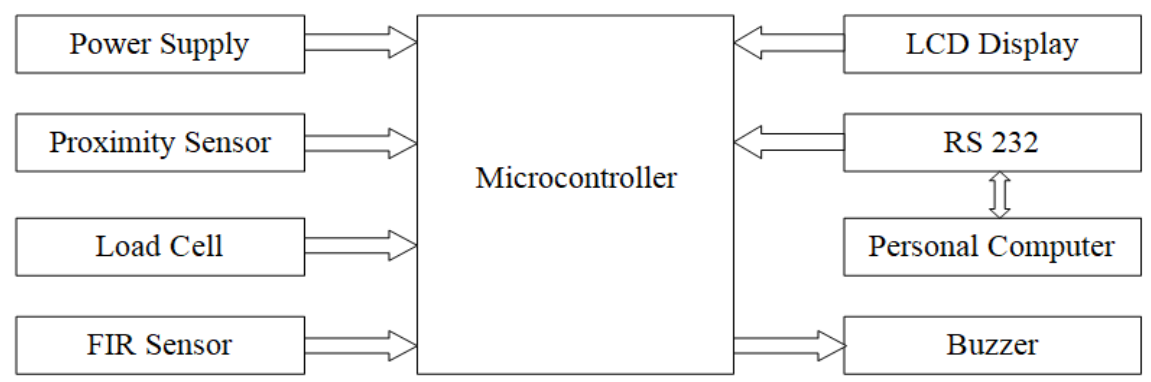

Fig.1Existing block diagram

\section{Proposed System}

The sketch of the projectedarrangement is exposed in Fig.2. It is having two units thecontrol unit and vehiclemonitoring system. The Arduino is used here to control the demo vehicle. The system is designed to monitor the driving skills of the candidate using Arduino[5]. The system works as follows. At the time of the test the candidate is authenticated using fingerprint. After the authentication is successful the candidate can proceed for test. The IR sensors are placed on the both sides of the track to check that vehicle is moving in specified path[6].

When the vehicle moves out of the specified track apulse is generated and is recorded by Arduino. Then according to the program written in the Arduino the failed LED will be turned on. Then, the buzzer alarm also will be indicated and the license will not be generated for that particular user.Here the user is reported as failed when the left detecting IR sensor and the right detecting IR sensor is detected. When vehicle completes the track without fail then the Pass LED will be turned on and the license will be generated automatically. The appropriate results such as pass and fail will be displayed in the LCD.

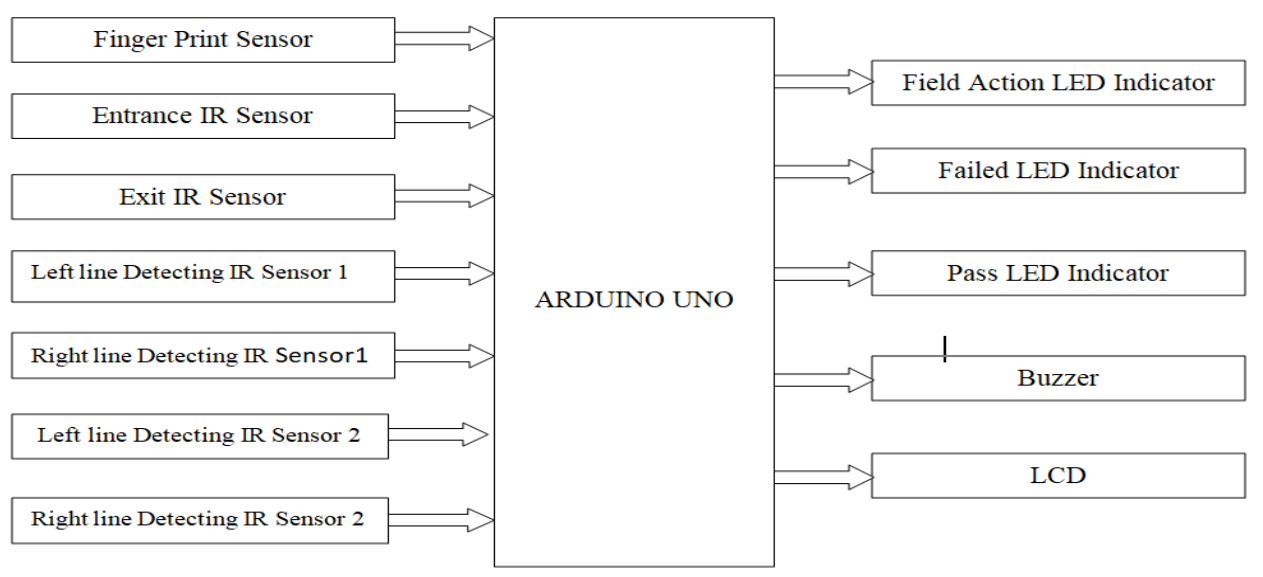

Fig.2.Proposed block diagram 


\section{Advantages}

This system is fully automated and no corruption due to transparency, Good Driving skills and no biasing.

\section{Camera Infrared System}

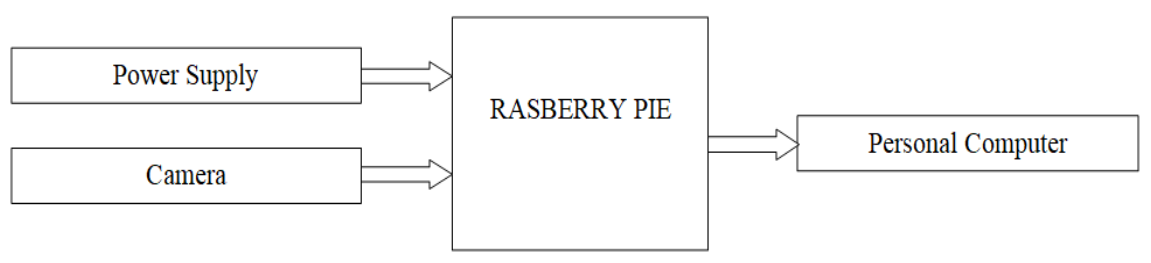

Fig.3.camera infrared system

Fig. 3 shows the infrared camera system which is connected with the personal computer through Rasberry Pie controller.

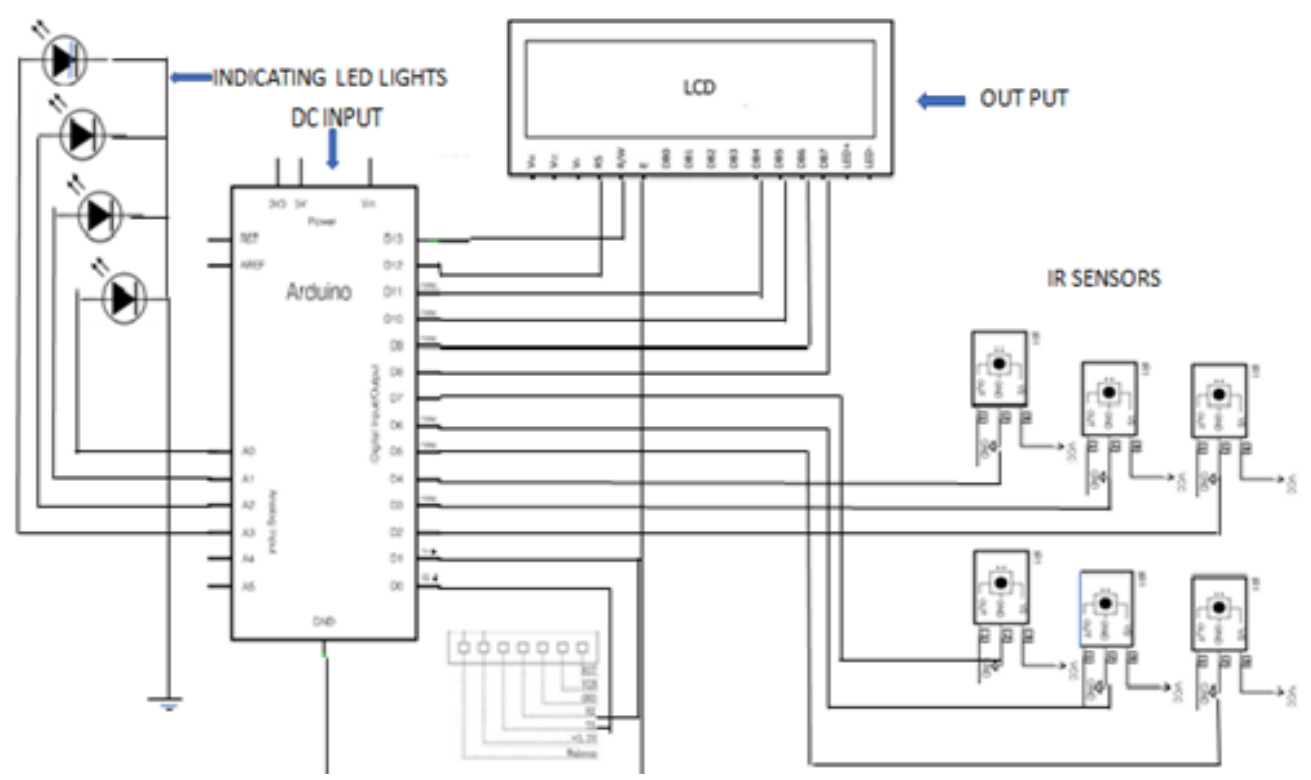

Fig.4.Circiut diagram of proposed system

The complete circuit layout of the projected model is shown in Fig.4. It consist of controller unit, driver unit, sensor unit and display unit.

\section{Step by Step Process Flow}




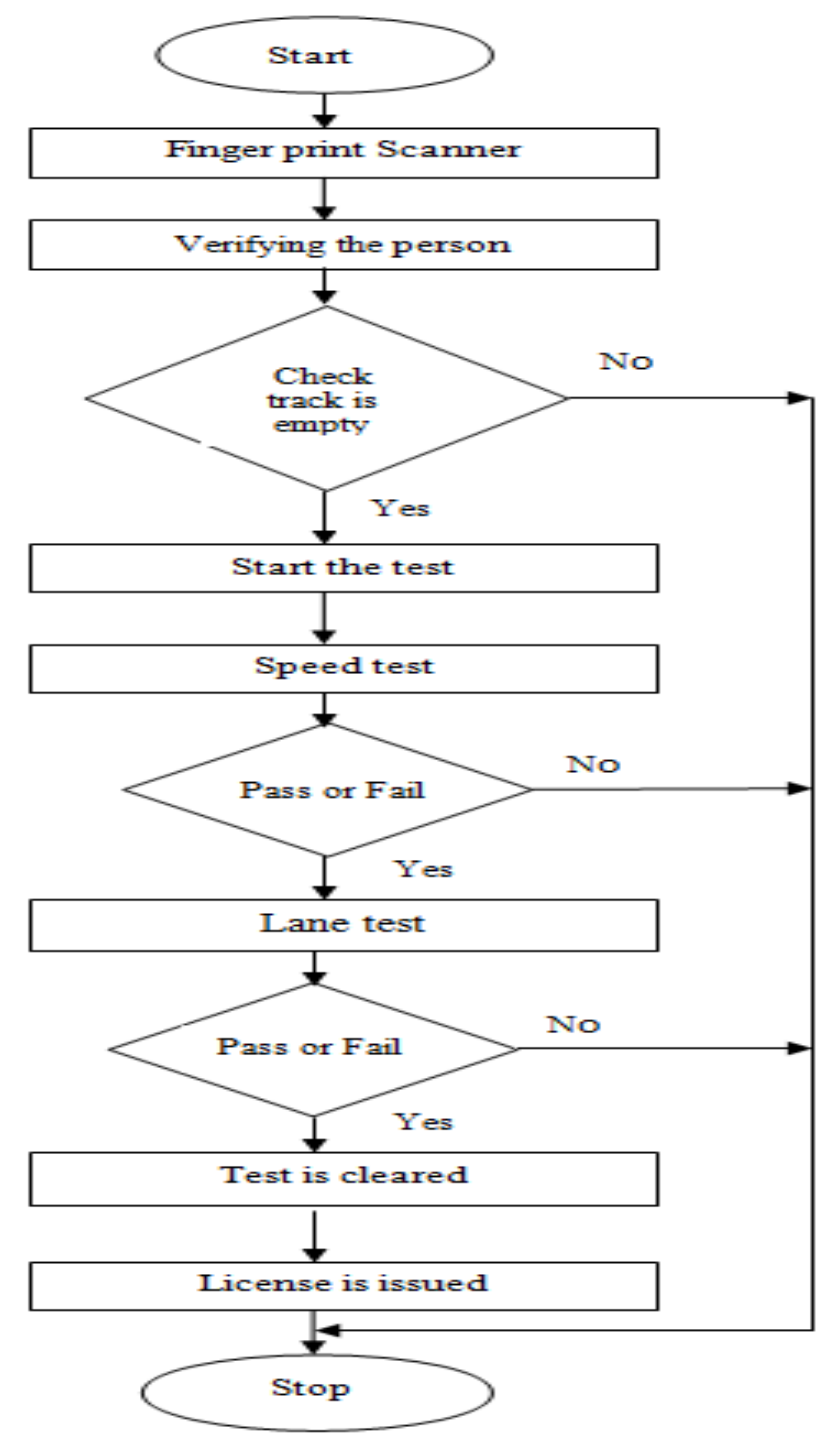

Fig .5.Flowchart of proposed system

Fig. 5 shows the step by step process flow of automatic license system

\section{$6 \quad$ Process of Working}

STEP1: Verifying the person with finger print scanner 


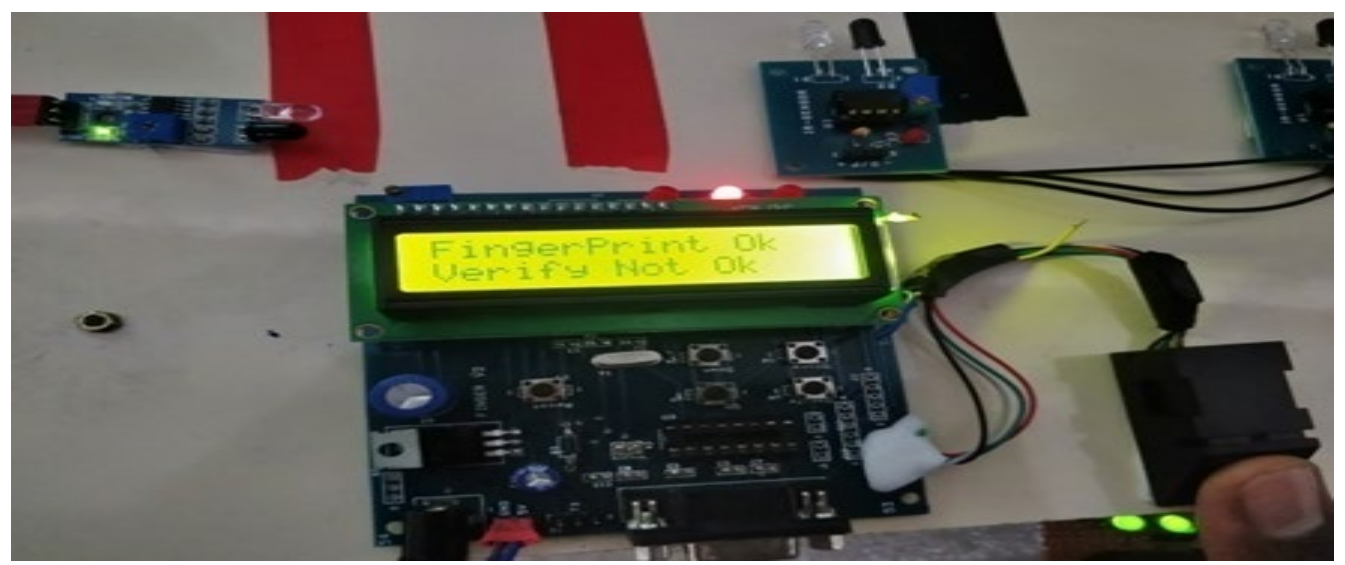

Fig.6.Finger print scanner

Checking any one is inside the testing track or not by seeing LED lights if green LED glows no one in the track (or) if red LED glows someone is inside the track.

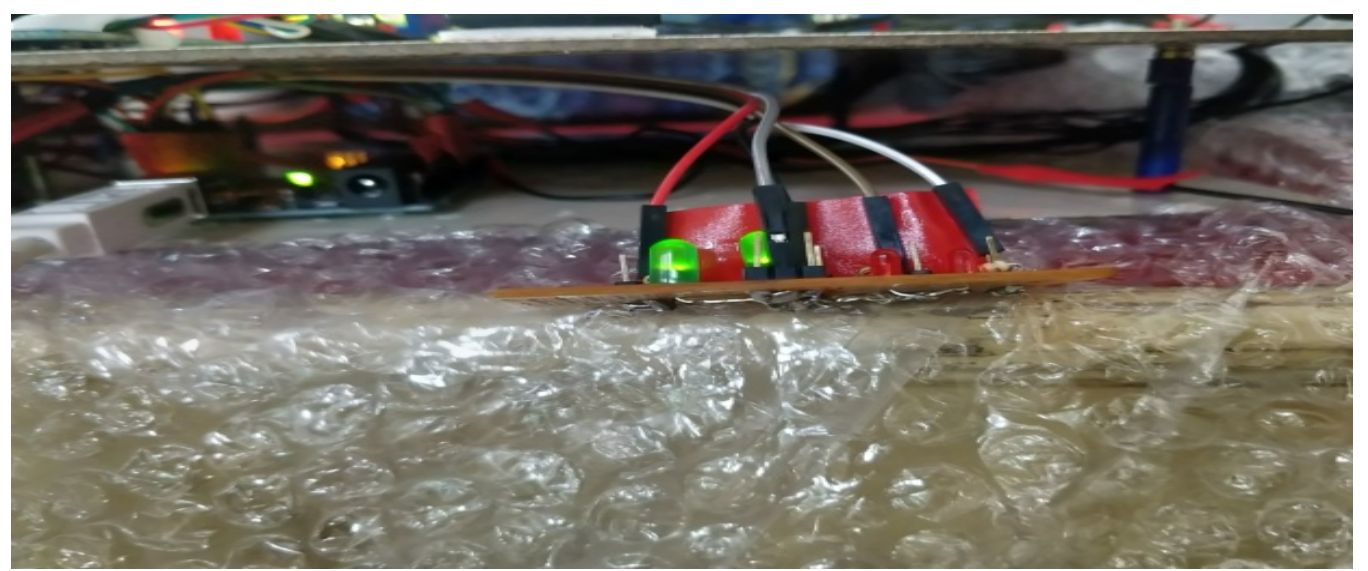

Fig.7. LED setup (OUT PUT)

Fig.6 shows the finger print scanning system to identify the person and verify his details. Fig.7 shows the LED setup to shows the output. 
STEP 2: Speed testing system

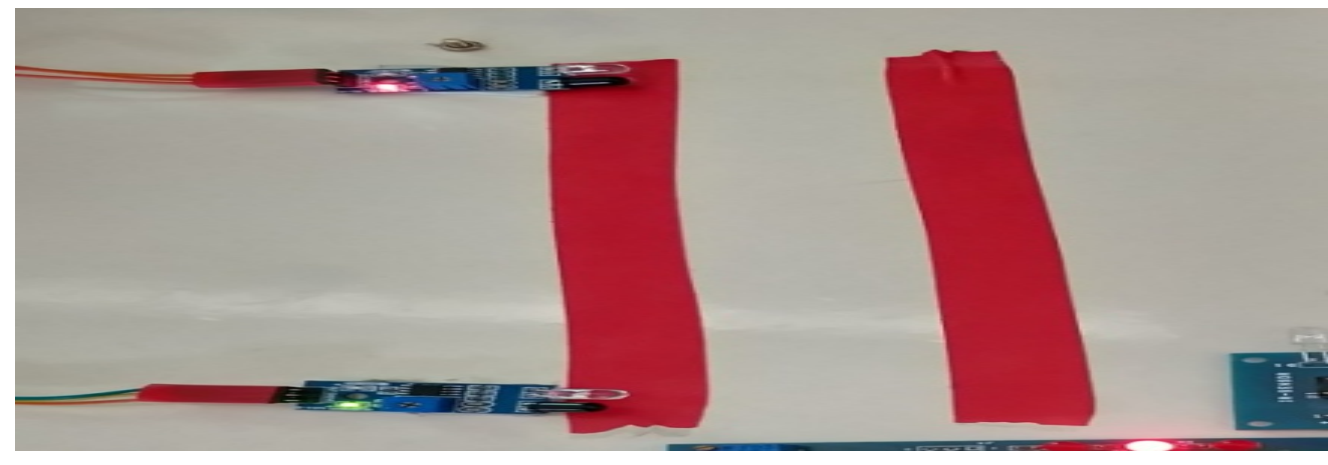

Fig.8.Speed test Track

After verifying the person with finger print scanning, checkanyone in the test track or not. If no one is in the track he/she start the test.Assume the place in between the red line is the test track IR sensors are placed at Start \&End of the track. Here green led shows first sensor and red led shows second sensor. The person he/she starts from first to second. When he/she crossed first one immediately timer starts. Each track having different timing. if and only if they crossed the track in prefixed time green light will glow and display test has been cleared (or) if he failed to cross the track with in time limit red light will glow and display time limit reached test has been failed.

STEP 3: Lane perfection test

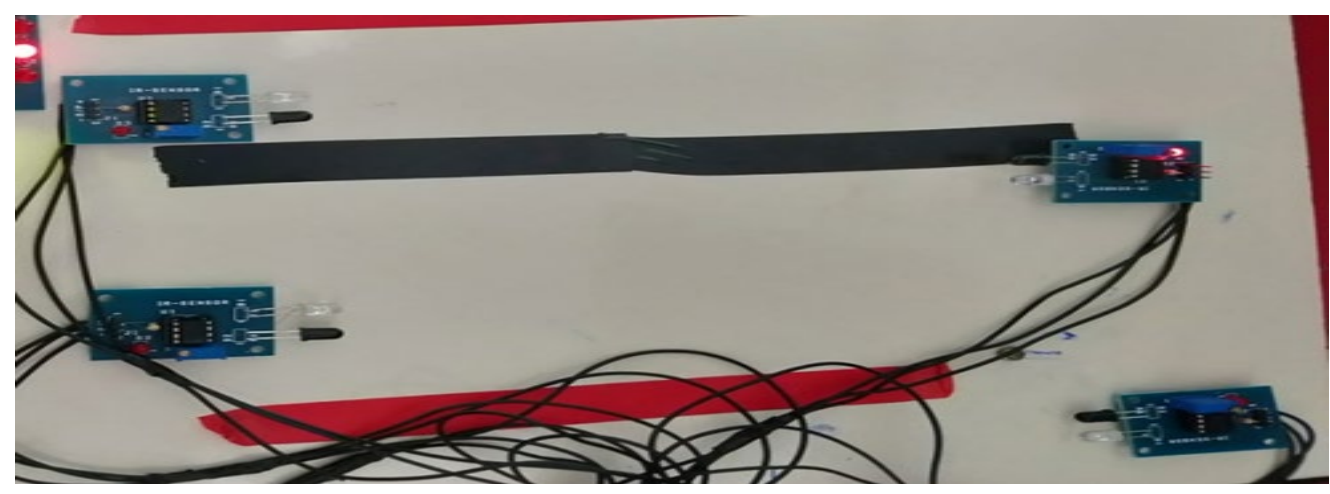

Fig.9. Lane perfection test circuit 
Both speed test and lane test will be on the same track for the clear idea we separated in to two tests. There will be separate lane sensing device for car and bike because they have different width. Above shown Fig.8 having 2 sensors on left and right and opposite to each other when ever the person cross the line from left side left IR sensor detects and shows red led light and also buzzer sound. Same as in right side also.If person fails to drive straight in the track fails the test.Apart of this there are 2 extra IR sensors will be present in the track it will use to identify IN and OUT of person those who are taking the test.

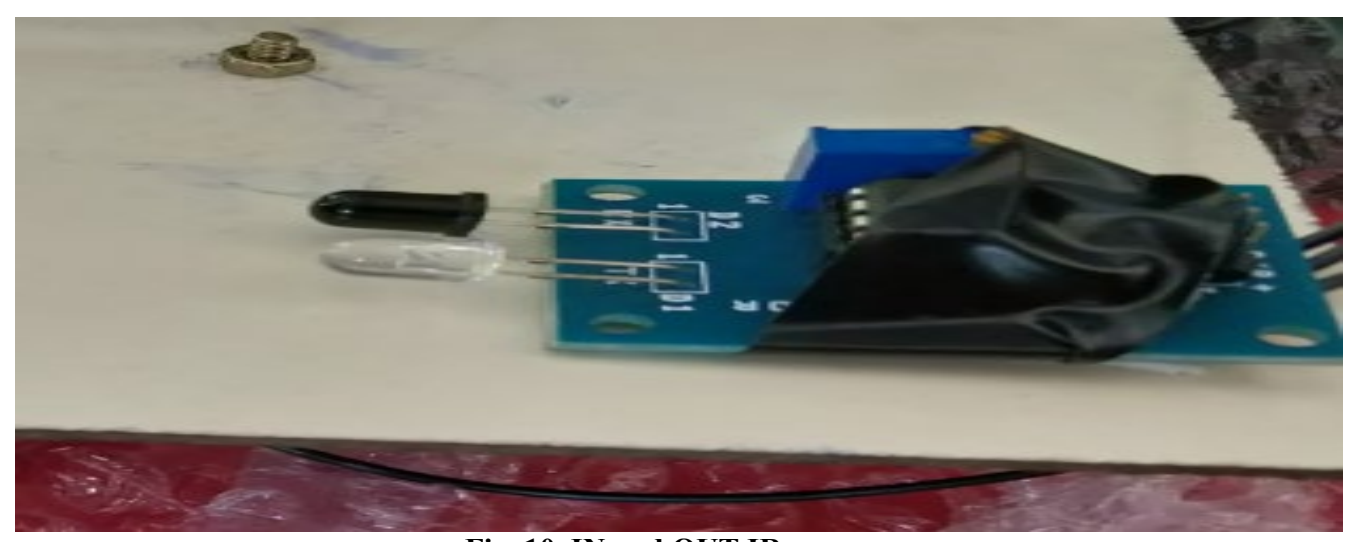

Fig .10. IN and OUT IR sensor

\section{Simulation Model for License Automation System}

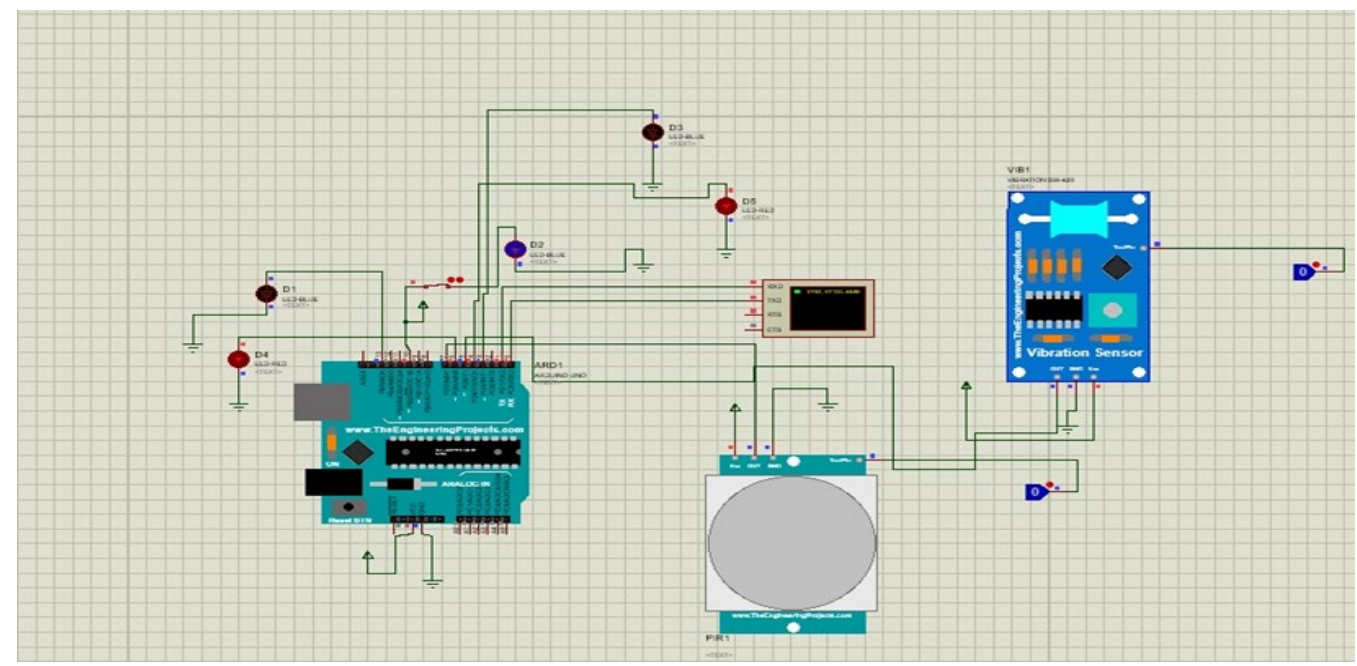

Fig .11. Simulation diagram for licence automation system 
Fig.11 shows the simulation model for license automation system developed by Proteus software.The process can be verified by the test cases discussed below.

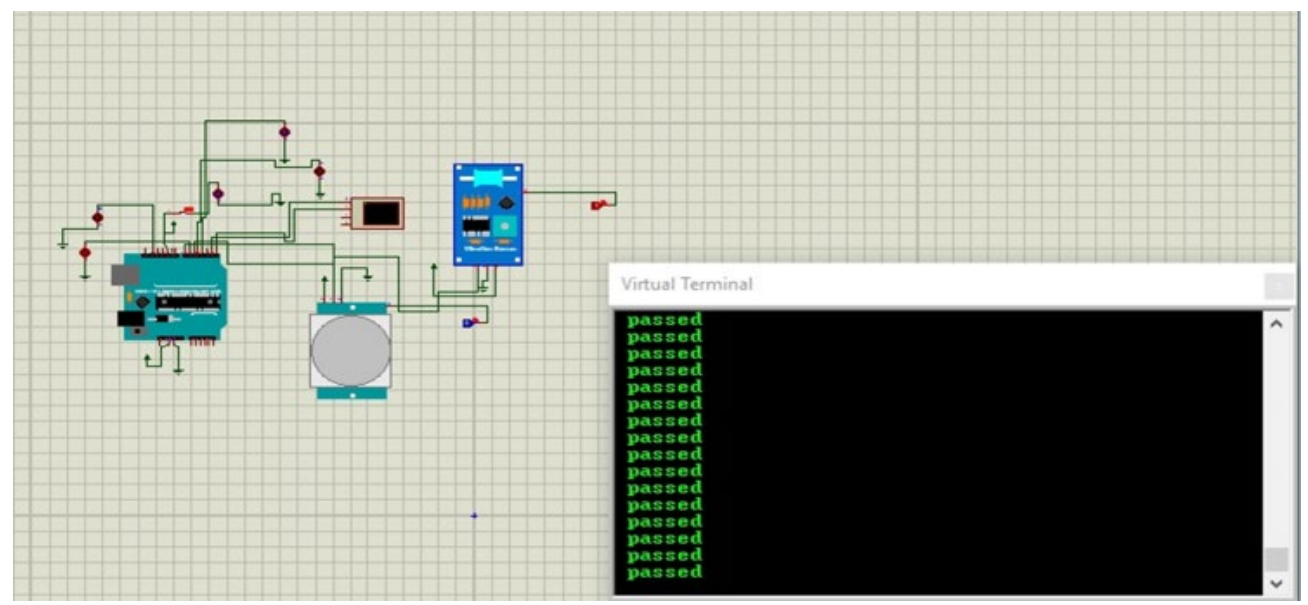

Fig.12.simulation results 1

RESULT 1: If the candidate cleared the entire test without any mistakes the result will be printed like shown below in LCD screen.

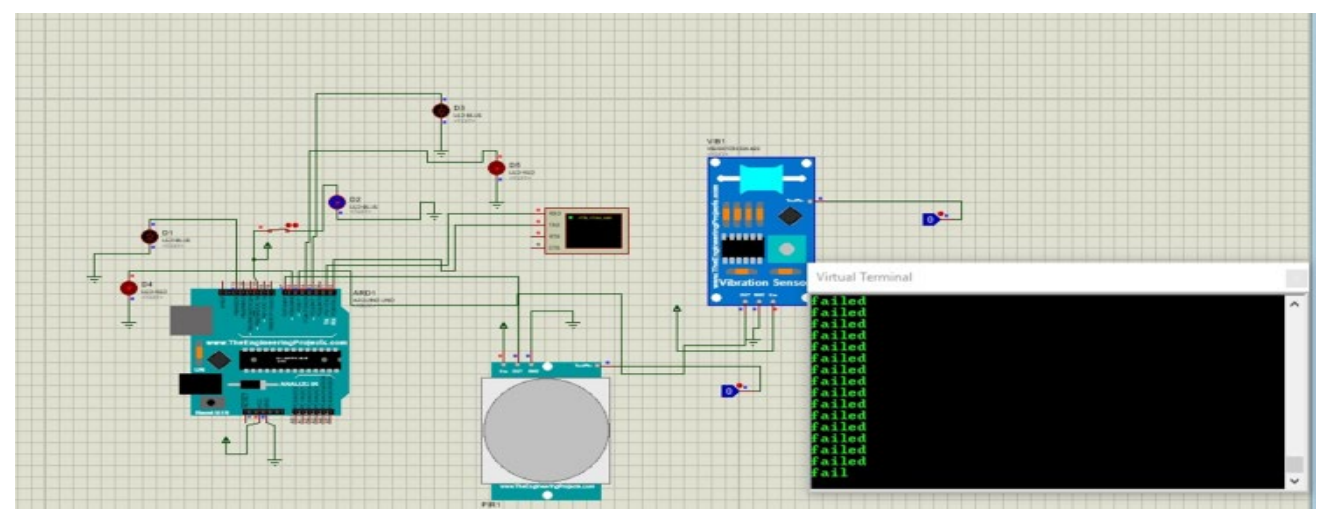

Fig .14.simulation result 2

RESULT 2: If the candidate is failed to complete the test the result will be displayed like shown below in LCD screen. 


\section{Conclusion}

Automated driving license system helps in selection of skilled drivers and also reduces the requirement of man power. The process of automation can be carried out and according to the performance of the candidate the license can be generated automatically. This automation system overcomes corruption and prevents accidents. The effectiveness of the system is validated and tested by the case studies tested by Proteus software. This system can be further enhaced and more features can be added with the help of Artificial Intelligence. So that the process time can be reduced and the cost of the system also may reduced.

\section{References}

[1] ArashFarad ,UsmanNisar, A.John , Miller,Lakshmish Ramaswamy , "Distributed And Scalable Graph Pattern matching:models and algorithms “,International Journal of Big Data,Volume 1,No.1, 2014

[2] D.Ramya, Santhi Mary Antony A, Godwin Immanuel D, “ Development of high precision with suitable hysteresis for automatic voltage regulator", International journal of Innovative technology and exploring engineering, Volume 8, Issue8 ,2019, pp. $801-804$.

[3] D.Ramya, Santhi Mary Antony A,Godwin Immanuel D, G.Nagaraja, "Design of interleaved flyback converter", International Journal of Intelligent Enterprise, Volume 6, No. 1, 2019, pp. 59 -76.

[4] Felix Endress, Jurgen Hess ,Jurgen Sturm, Daniel Cremer and WolfarmBurgard, "3D Mapping with an RGBD Camera" IEEE Transaction On Robotics,Vol.30,Ferruary 2014.

[5] Jae SeokYang, Seungpil Kang , Kyungsoo Chon” The Map Matching Algorithm of GPS Data With Relatively Long Polling Time Intervals "Journal of the Eastern Asia Society for Transportation Studies, Volume 6, pp. $2561-2573$.

[6] Conde Bento, Urbano Nunes, Fernando Moita and AntonioSurrecio, "Sensor Fusion for Precise Autonomous Vehicle Navigation in Outdoor Semi-structured Environments", IEEE Conference on Intelligent Transportation Systems Vienna, Austria, 2005. 